\title{
Calibration effects of the net longwave radiation equation in Penman-type methods at Tateno, Japan
}

\author{
Hiroyuki Matsui and Kazutoshi Osawa \\ Faculty of Agriculture, Utsunomiya University, Japan
}

\begin{abstract}
:
Penman-type evapotranspiration (ET) methods are widely used in irrigation water management and water resource planning. To determine the daily reference ET using Penmantype methods, net longwave radiation must be estimated through an empirical net longwave radiation equation based on meteorological data. This paper presents the coefficients of the net longwave radiation equation calibrated using highly accurate data observed at the Tateno observatory, which belongs to the Baseline Surface Radiation Network (BSRN). The daily net longwave radiation calculated with these calibrated coefficients is in better agreement with the observed data as compared with those of the original Penman-Monteith equation in the Food and Agriculture Organization (FAO) Irrigation and Drainage Paper no. 56 (FAO56-PM). In particular, the FAO56-PM cloudiness factor coefficients are more effectively calibrated in this study. The annual mean reference ET calculated through the calibrated FAO56-PM corresponds to approximately $90 \%$ of the values calculated using the original coefficients.
\end{abstract}

KEYWORDS evapotranspiration; net longwave radiation; Penman-Monteith equation; BSRN; recalibration

\section{INTRODUCTION}

Crop water requirements are determined by the pan evaporation, the Blaney-Criddle, or Penman-type methods. Penman-type methods are widely used in water resource planning and irrigation water management. Among them, the Penman-Monteith equation described in the Food and Agriculture Organization (FAO) Irrigation and Drainage Paper no. 56 (FAO56-PM; Allen et al., 1998) is recognized as an accurate and useful method. The FAO56-PM and CROPWAT irrigation management tool (Smith, 1991), which is based on the FAO56-PM, were applied to many Asian countries and regions, e.g., China (Gong et al., 2006), South Korea (Yoo et al., 2008), and Taiwan (Kuo et al., 2006).

The net radiation is the balance between the downward and upward shortwave and longwave radiation, and it is influenced by clouds, water vapor, aerosols, carbon dioxide, and trace gases (Arking, 1991; Monteith and Unsworth, 2007). The estimation of net radiation is an essential prerequisite for applying the Penman methods. The net shortwave radiation can be reliably obtained since the downward shortwave radiation is recorded at many meteorological stations. In addition, albedo values, which determine the upward shortwave radiation, vary narrowly between 0.20 and 0.25 (Brutsaert, 1982). In contrast, accurate longwave radiation data are limited. Moreover, Allen (2008) mentioned that it is hard to satisfy the measurement prerequisites: the reference surface defined by the FAO expert consultation (Allen et al., 1998), a highly accurate radiometer, and clean radiometer domes. Therefore, the net longwave radiation is commonly calculated by a net longwave radiation equation consisting of meteorological variables: water vapor pressure, air temperature, and downward shortwave radiation or sunshine duration.

The net longwave radiation equation coefficients suggested in the FAO56-PM have been applied under various situations in many countries and regions, but they required calibration in each case with the local observation data (Jensen et al., 1990; Allen et al., 1998; Yin et al., 2008; Kjaersgaard et al., 2009). Literature on calibration of these coefficients using accurate longwave radiation data was not found in Japan. Baseline Surface Radiation Network (BSRN) stations provide highly accurate downward and upward longwave radiation data (Ohmura et al., 1998), although the upward longwave radiation on the reference surface is not directly measured at the stations. BSRN data can help to calibrate the coefficients used in FAO56-PM methods. The objectives of this study are to verify the performance of the original FAO56-PM longwave radiation equation using data observed at the Tateno station, which is registered as a BSRN station, to calibrate the coefficients used in the FAO56-PM net longwave radiation equation in order to find the coefficients adapted to meteorological conditions at Tateno, and to assess the calibration effects for net emissivity and cloudiness factor in the equation on the estimation accuracies of the net longwave radiation and the reference ET.

\section{MATERIALS AND METHODS}

\section{Meteorological data}

Meteorological data, including longwave radiation, were recorded at the Tateno aerological observatory $\left(36^{\circ} 3.4^{\prime} \mathrm{N}\right.$, $140^{\circ} 7.5^{\prime} \mathrm{E}$; Figure 1) in Tsukuba, Japan, from 1998 through 2012. The observatory is registered as a BSRN station, and it records the longwave radiation with a root mean square error (RMSE) of $<1.0 \mathrm{~W} \mathrm{~m}^{-2}$ (Ohmura et al., 1998; Ohkawara and Takano, 2008). We converted the 1 minute-based radiation data (0:00 to $24: 00)$ to daily averages excluding only the records for days when it had snowed and snow cover days. Other meteorological data in this paper were converted from hourly to daily data. The climate at the station is humid subtropical according to the Köppen climate classification.

Received 31 August, 2015 Accepted 10 November, 2015 


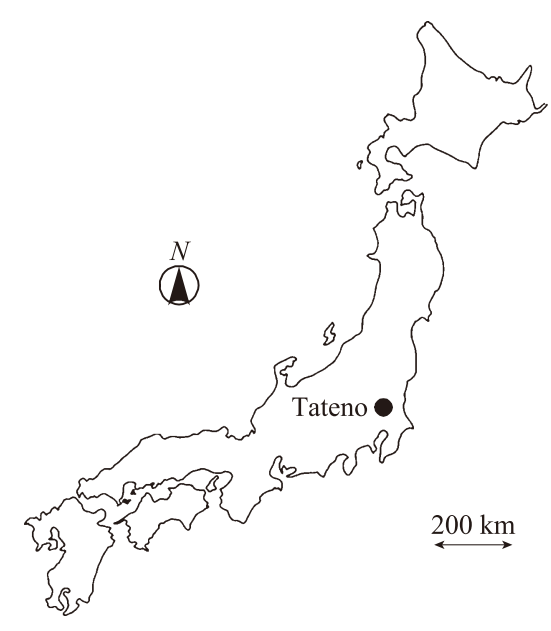

Figure 1. Location of the Tateno aerological observatory

FAO expert consultation requires meteorological observations on the reference surface to determine the reference evapotranspiration (Allen et al., 1998). Allen et al. (1998) described that the reference surface is an extensive surface of green grass of uniform height, active growing, completely shading the ground and with adequate water. The upward longwave radiation at Tateno is observed on the clipped grass without irrigation, not on the reference surface. Then, assuming that the surface of clipped grass following the days after heavy rainfall (i.e., $>20 \mathrm{~mm} \mathrm{~d}^{-1}$ ) was well watered and similar to the reference surface, the estimated net longwave radiation $\left(R_{\mathrm{nl}}\right)$ was compared with the selected records.

\section{Net longwave radiation methods}

The $R_{\mathrm{nl}}$ in Penman-type ET methods is calculated by determining the net longwave radiation through a clear sky, and then adjusting the value for cloud cover. The equation in $\mathrm{MJ} \mathrm{m}^{-2} \mathrm{~d}^{-1}$ (Brunt, 1932; Penman, 1948; Jensen et al., 1990; Allen et al., 1998) can be written as

$$
R_{\mathrm{nl}}=\sigma\left(\frac{T_{\max }{ }^{4}+T_{\min }{ }^{4}}{2}\right) \varepsilon_{\text {net }} f
$$

where $\sigma$ is the Stefan-Boltzmann constant $\left(\mathrm{MJ} \mathrm{m}^{-2} \mathrm{~d}^{-1} \mathrm{~K}^{-4}\right)$, $T_{\max }$ and $T_{\min }$ are the daily maximum and minimum air temperatures at $2 \mathrm{~m}$ height $(\mathrm{K})$, respectively, $\varepsilon_{\text {net }}$ is the net emissivity, and $f$ is the cloudiness factor. The value of $\varepsilon_{\text {net }}$ is calculated as the emissivity by vegetation $\left(\varepsilon_{\mathrm{vs}}\right)$ minus the atmospheric emissivity $\left(\varepsilon_{\mathrm{a}}\right)$ using Equation (2):

$$
\varepsilon_{\mathrm{net}}=\varepsilon_{\mathrm{vs}}-\varepsilon_{\mathrm{a}}
$$

The coefficient $\varepsilon_{\mathrm{vs}}$ is commonly assumed to be 0.98 , and $\varepsilon_{\mathrm{a}}$ is obtained by applying the Brunt equation:

$$
\varepsilon_{\mathrm{a}}=a_{1}+b_{1} \sqrt{e_{\mathrm{a}}}
$$

where $a_{1}$ and $b_{1}$ are coefficients, and $e_{\mathrm{a}}$ is the water vapor pressure $(\mathrm{kPa})$. The cloudiness factor $(f)$ is

$$
f=a_{2(1)} \frac{n}{N}+b_{2(1)}
$$

or

$$
f=a_{2(2)} \frac{R_{\mathrm{s}}}{R_{\mathrm{so}}}+b_{2(2)}
$$

where,

$$
\begin{aligned}
& R_{\mathrm{s}}=\left(a_{3}+b_{3} \frac{n}{N}\right) R_{\mathrm{a}} \\
& R_{\mathrm{so}}=\left(a_{3}+b_{3}\right) R_{\mathrm{a}} \\
& a_{2(2)}=a_{2(1)} \frac{\left(a_{3}+b_{3}\right)}{b_{3}} \\
& b_{2(2)}=-a_{2(1)} \frac{a_{3}}{b_{3}}+b_{2(1)}
\end{aligned}
$$

here $a_{2(1)}, a_{2(2)}, b_{2(1)}, b_{2(2)}, a_{3}$, and $b_{3}$ are coefficients, $R_{\mathrm{s}}$ is the solar radiation ( $\left.\mathrm{MJ} \mathrm{m}^{-2} \mathrm{~d}^{-1}\right), R_{\mathrm{so}}$ is the clear sky solar radiation $\left(\mathrm{MJ} \mathrm{m}^{-2} \mathrm{~d}^{-1}\right), R_{\mathrm{a}}$ is the extraterrestrial solar radiation $(\mathrm{MJ}$ $\left.\mathrm{m}^{-2} \mathrm{~d}^{-1}\right), n$ is the actual sunshine duration (h), and $N$ is the maximum possible sunshine duration (h). Equation (6) is known as the Ångström equation. Penman (1948) and Jensen et al. (1990) applied Equation (4) with $a_{2(1)}=0.9$ and $b_{2(1)}=$ 0.1 . By taking account of this equation, Allen et al. (1998) applied Equation (5) with $a_{2(2)}=1.35$ and $b_{2(2)}=-0.35$ which are obtained by substituting Equation (6) with $a_{3}=0.25$ and $b_{3}=0.50$ and Equation (7) into Equation (4) with the values of coefficients suggested by Penman (1948) and Jensen et al. (1990). In this study, Equation (5) is adopted for the cloudiness factor. Coefficients $\left(a_{2(2)}\right.$ and $\left.b_{2(2)}\right)$ are fitting parameters (Allen et al., 1994), whereas $a_{3}$ and $b_{3}$ are determined through regression analysis. The sum of $a_{2(2)}$ and $b_{2(2)}$ is optimum at 1.0 .

In this study, three sequential procedures are performed (Table I). First, the two coefficients $\left(a_{1}\right.$ and $\left.b_{1}\right)$ in Equation (3) are calibrated to minimize the RMSE of the estimated longwave downward radiation with respect to the longwave downward radiation during clear sky days, when the relative sunshine hour is greater than 0.95 (step 1). Then, with $a_{1}$ and $b_{1}$ fixed to the calibrated values in step 1 , the two site-specific coefficients $\left(a_{3}\right.$ and $\left.b_{3}\right)$ in the Ångström equation are calibrated to minimize the RMSE of the estimated solar radiation (step 2). Through step 2, values of coefficients $\left(a_{2(2)}\right.$ and $\left.b_{2(2)}\right)$ are calculated by Equations (8) and (9) using values of $a_{2(1)}$ and $b_{2(1)}$ suggested by Penman (1948) and Jensen et al. (1990). Finally, in step 3, $a_{2(2)}$ and $b_{2(2)}$ in Equation (5) are directly calibrated with coefficients $\left(a_{1}\right.$ and $\left.b_{1}\right)$ obtained in step 1 and $\left(a_{3}+b_{3}\right)$ obtained in step 2 to minimize the RMSE of the estimated net longwave radiation with respect to the observed records.

\section{Analytical methods}

The calibration performance was evaluated by the RMSE of the estimated net longwave radiation $\left(R_{\mathrm{nl}, \text { est }}\right)$ and the mean bias error (MBE) of $R_{\mathrm{nl}, \text { est }}$ using the calibrated coefficients. The RMSE and MBE are calculated by

$$
\begin{aligned}
& R M S E=\sqrt{\frac{1}{N} \sum\left(R_{\mathrm{nl}, \mathrm{obs}}-R_{\mathrm{nl}, \mathrm{est}}\right)^{2}} \\
& M B E=\frac{1}{N} \sum\left(R_{\mathrm{nl}, \mathrm{obs}}-R_{\mathrm{nl}, \mathrm{est}}\right)
\end{aligned}
$$

where $R_{\mathrm{nl}, \mathrm{obs}}$ is the observed net longwave radiation.

In addition, the difference of the reference ET between the original $R_{\mathrm{nl}}$ calculation in the FAO56-PM and the modified 
Table I. Structure of the calibration steps used to compute the net long wave radiation $\left(R_{\mathrm{nl}}\right)$ as a function of the variables and constants

\begin{tabular}{ccccc}
\hline & \multicolumn{2}{c}{$f$} & $\varepsilon_{\mathrm{a}}$ \\
\cline { 2 - 5 } Step & $a_{1}$ and $b_{1}$ & $a_{2(1)}$ and $b_{2(1)}$ & $a_{2(2)}$ and $b_{2(2)}$ & $a_{3}$ and $b_{3}$ \\
\hline $0^{[a]}$ & $a_{1}=0.64 ; b_{1}=0.14$ & $a_{2(1)}=0.9 ; b_{2(1)}=0.1^{[b]}$ & $a_{2(2)}=1.35 ; b_{2(2)}=-0.35$ & $a_{3}=0.25 ; b_{3}=0.50$ \\
1 & Calibrated & $a_{2(1)}=0.9 ; b_{2(1)}=0.1^{[b]}$ & $a_{2(2)}=1.35 ; b_{2(2)}=-0.35$ & $a_{3}=0.25 ; b_{3}=0.50$ \\
2 & Calibrated in Step 1 & $a_{2(1)}=0.9 ; b_{2(1)}=0.1^{[b]}$ & $a_{2(2)}=1.24 ; b_{2(2)}=-0.24^{[\mathrm{cc}]}$ & Calibrated \\
3 & Calibrated in Step 1 & - & Calibrated & Calibrated in Step 2 \\
\hline
\end{tabular}

[a] All values are the same as in the FAO56-PM equation.

[b] These values are not explicitly used in the $R_{\mathrm{nl}}$ calculation.

[c] Coefficients $a_{2(2)}$ and $b_{2(2)}$ are calculated by Equations (8) and (9).

Table II. Calibrated coefficients in each step

\begin{tabular}{ccccc}
\hline Step & \multicolumn{4}{c}{ Coefficients } \\
\hline 1 & $a_{1}$ & 0.61 & $b_{1}$ & 0.16 \\
2 & $a_{3}$ & 0.21 & $b_{3}$ & 0.55 \\
3 & $a_{2(2)}$ & 0.83 & $b_{2(2)}$ & 0.17 \\
\hline
\end{tabular}

calculation adopting the calibrated coefficients (DifET) was calculated by Equation (12):

$$
\text { DifET }=-\frac{0.408 \Delta}{\Delta+\gamma\left(1+0.34 u_{2}\right)}\left(R_{\mathrm{nl}, 0}-R_{\mathrm{nl}, \mathrm{i}}\right)
$$

where $R_{\mathrm{nl}, 0}$ is the net longwave radiation estimated with the original coefficients (step 0 in Table I), $R_{\mathrm{nl}, \mathrm{i}}$ is the net longwave radiation estimated with the calibrated coefficients of the steps $\mathrm{i} ; 1,2$, and 3 in Table I, $\Delta$ is the slope of the saturation vapor pressure-temperature curve, $\gamma$ is the psychromet-

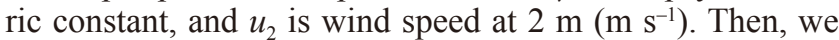
evaluated the effect of the calibration on the monthly and annual reference ET.

\section{RESULTS AND DISCUSSION}

\section{Calibrated coefficients}

Table II presents the calibrated coefficients values produced by each step. The coefficients of the Brunt equation are $a_{1}=0.61$ and $b_{1}=0.16$ during clear sky days (i.e., $n=$ 450 days) as determined by step 1 . These coefficient values are within the general range $\left(0.54<a_{1}<0.64\right.$ and $0.14<b_{1}$ $<0.25$; Allen, 1994). The estimated downward longwave radiation has a RMSE of $0.60 \mathrm{MJ} \mathrm{m}^{-2} \mathrm{~d}^{-1}$, with respect to the observed downward longwave radiation. Consequently, the net emissivity $\left(\varepsilon_{\text {net }}\right)$ equation is

$$
\varepsilon_{\text {net }}=0.98-\left(0.61+0.16 \sqrt{e_{\mathrm{a}}}\right)=0.37-0.16 \sqrt{e_{\mathrm{a}}}
$$

The coefficients of the Ångström equation for estimating the solar radiation are $a_{3}=0.21$ and $b_{3}=0.55$ according to step $2(n=5,078$ days $)$. The estimated solar radiation has a RMSE of $1.89 \mathrm{MJ} \mathrm{m}^{-2} \mathrm{~d}^{-1}$, with respect to the observed solar radiation. $R_{\mathrm{so}}$ obtained by Equation (7) should plot as an upper envelope of observed $R_{\mathrm{s}}$ (Allen et al., 1998). The time-series data of $R_{\mathrm{so}}$ obtained by Equation (7) with these coefficients
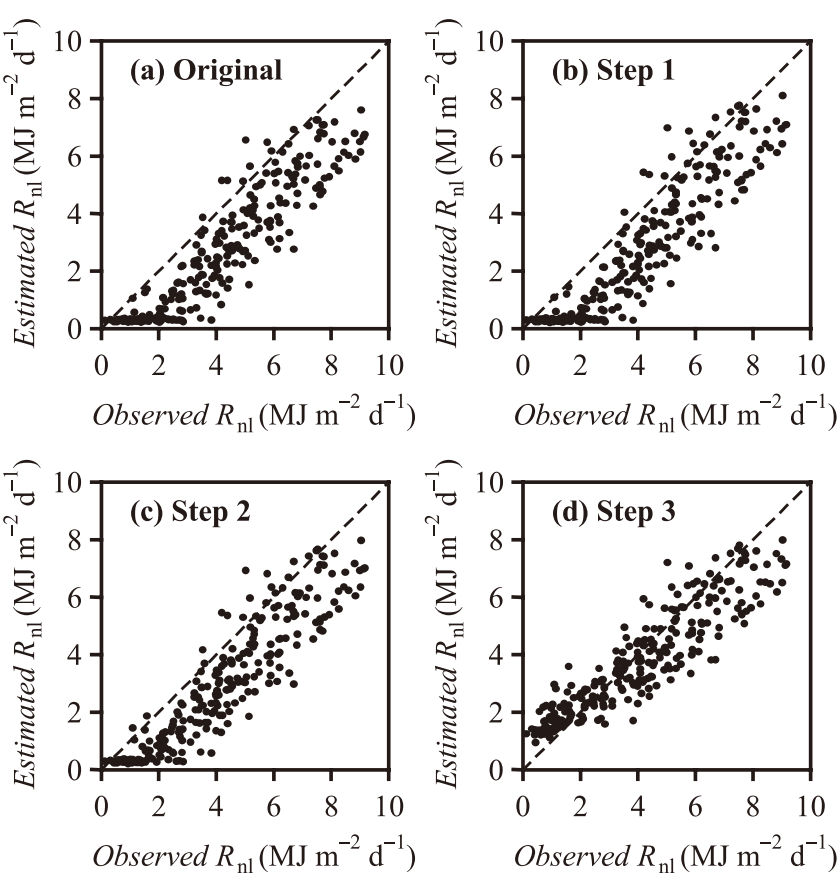

Figure 2. Relationship between the different $R_{\mathrm{nl}, \mathrm{i}}$ using the original and/or calibrated coefficients in each step, and the observed net longwave radiation $R_{\mathrm{nl}, \mathrm{obs}}$ on the hypothetical surface for 15 years (1998-2012). The dotted line shows the $1: 1$ line

envelop $99.8 \%$ of solar radiation records. By this calibration, the ratio of $R_{\mathrm{so}} / R_{\mathrm{a}}$ is 0.76 , and the values of $a_{2(2)}$ and $b_{2(2)}$ change to 1.24 and -0.24 , respectively. The coefficients in Equation (5) are $a_{2(2)}=0.83$ and $b_{2(2)}=0.17$ according to step 3 ( $n=262$ days). The coefficient $b_{2(2)}$ is determined so that the sum of $a_{2(2)}$ and $b_{2(2)}$ becomes 1.0 (Allen et al., 1994).

Comparison between the observed and estimated $R_{n l}$

Figure 2 presents the estimated $R_{\mathrm{nl}}$, using the original coefficients and/or the calibrated coefficients by each step, against the observed $R_{\mathrm{nl}}$ on the hypothetical reference surface. The monthly mean differences between the estimated and observed $R_{\mathrm{nl}}$ are presented in Figure 3. The results of the statistical analysis of the estimated $R_{\mathrm{nl}}$ appear in Table III. The estimated $R_{\mathrm{n} 1,0}$ by the original FAO56-PM (step 0 ) has a RMSE of $1.72 \mathrm{MJ} \mathrm{m}^{-2} \mathrm{~d}^{-1}$ and MBE of $-1.44 \mathrm{MJ} \mathrm{m}^{-2} \mathrm{~d}^{-1}$. 


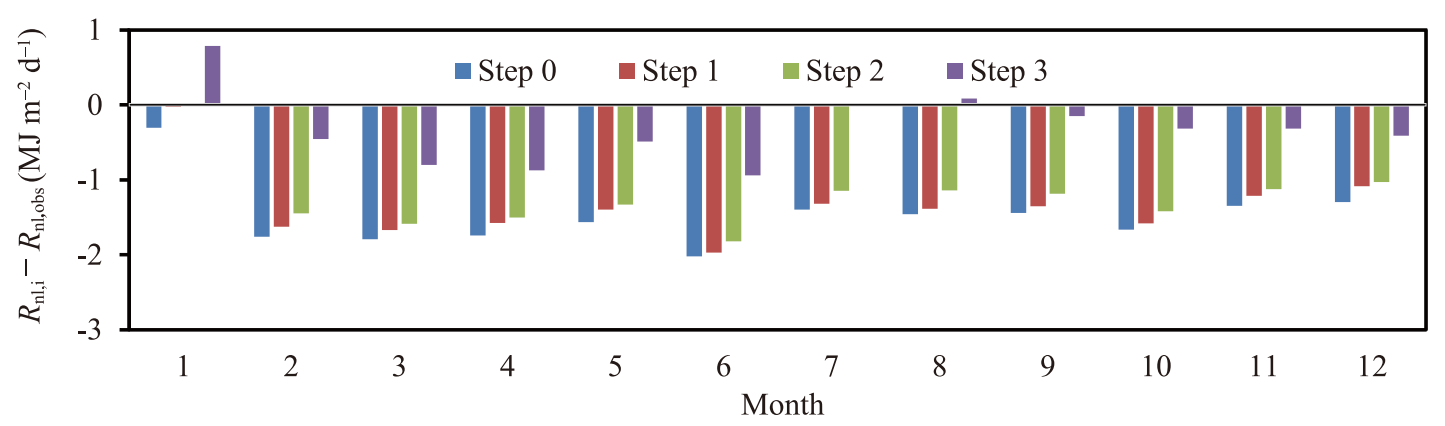

Figure 3. Monthly mean difference between the estimated and observed net longwave radiation for 15 years (1998-2012)

Table III. Statistical results of the difference between the net longwave radiation $\left(R_{\mathrm{nl}, \mathrm{i}}\right)$ estimated by each step and the observed net longwave radiation $\left(R_{\mathrm{nl}, \mathrm{obs}}\right)$ for 15 years (1998-2012)

\begin{tabular}{ccc}
\hline Step & RMSE $\left(\mathrm{MJ} \mathrm{m}^{-2} \mathrm{~d}^{-1}\right)$ & $\mathrm{MBE}\left(\mathrm{MJ} \mathrm{m}^{-2} \mathrm{~d}^{-1}\right)$ \\
\hline 0 & 1.72 & -1.44 \\
1 & 1.66 & -1.34 \\
2 & 1.55 & -1.23 \\
3 & 1.11 & -0.34 \\
\hline
\end{tabular}

The $R_{\mathrm{nl}, 0}$ tends to underestimate the net longwave radiation throughout the year. The monthly mean differences are greater than $-1.0 \mathrm{MJ} \mathrm{m}^{-2} \mathrm{~d}^{-1}$, except for January. These negative differences indicate that the reference ET is possibly overestimated. The underestimation of the $R_{\mathrm{nl}}$ by the FAO56-PM method was also reported in China (Yin et al., 2008). The $R_{\mathrm{nl}, 1}$ estimated by step 1 has a RMSE of $1.66 \mathrm{MJ} \mathrm{m}^{-2} \mathrm{~d}^{-1}$ and MBE of $-1.34 \mathrm{MJ} \mathrm{m}^{-2} \mathrm{~d}^{-1}$, whereas $R_{\mathrm{nl}, 2}$ has a RMSE of $1.55 \mathrm{MJ} \mathrm{m}^{-2} \mathrm{~d}^{-1}$ and MBE of $-1.23 \mathrm{MJ} \mathrm{m}^{-2} \mathrm{~d}^{-1}$. The monthly mean differences for $R_{\mathrm{nl}, 1}$ and $R_{\mathrm{nl}, 2}$ are improved in all months, as compared with those following step 0 . Finally, $R_{\mathrm{nl}, 3}$ has a RMSE of $1.11 \mathrm{MJ} \mathrm{m}^{-2} \mathrm{~d}^{-1}$ and MBE of $-0.34 \mathrm{MJ} \mathrm{m}^{-2} \mathrm{~d}^{-1}$, producing the best statistical results from all steps. The MBE is improved from $-1.44 \mathrm{MJ} \mathrm{m}^{-2} \mathrm{~d}^{-1}$, in step 0 , to $-0.34 \mathrm{MJ} \mathrm{m}^{-2} \mathrm{~d}^{-1}$, in step 3 , since the underestimation of $R_{\mathrm{nl}}$ is mitigated by using this step. The RMSE of estimated $R_{\mathrm{nl}}$ in the five ranges of the $R_{\mathrm{s}} / R_{\mathrm{so}}$ ratio is presented in Figure 4 . The relationships between the cloudiness factor $(f)$ in steps 0 and 3 and the ratio of solar radiation to clear sky solar radiation $\left(R_{\mathrm{s}} / R_{\mathrm{so}}\right)$ are presented in Figure 5 . For $R_{\mathrm{s}} / R_{\mathrm{so}}$ from 0.2 to 0.8 (Figure 4), the RMSE differences between $R_{\mathrm{nl}, 0}$ and $R_{\mathrm{nl}, 3}$ are greater than those for other $R_{\mathrm{s}} / R_{\mathrm{so}}$ ranges. The $R_{\mathrm{s}} / R_{\mathrm{so}}=0.2-0.8$ range corresponds to the range where the $f$ values in step 3 deviate from the $f$ values in step 0 (Figure 5). Therefore, the RMSE and MBE are improved using step 3 because the cloudiness factor are adjusted in the $\left(R_{\mathrm{s}} / R_{\mathrm{so}}\right)$ range from 0.2 to 0.8 .

Hence, the equation that we recommended for the net longwave radiation at Tateno is

$$
R_{\mathrm{nl}}=\sigma\left(\frac{T_{\max }{ }^{4}+T_{\min }{ }^{4}}{2}\right)\left(0.37-0.16 \sqrt{e_{\mathrm{a}}}\right)\left(0.83 \frac{R_{\mathrm{s}}}{R_{\mathrm{so}}}+0.17\right)
$$

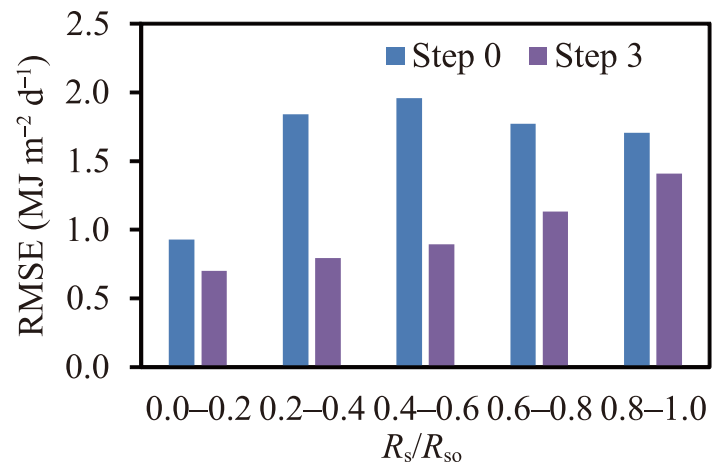

Figure 4. RMSE of the estimated net longwave radiation in the ratio of the solar radiation to the clear sky solar radiation $\left(R_{\mathrm{s}} / R_{\mathrm{so}}\right), \mathrm{N}=56\left(0.0 \leq R_{\mathrm{s}} / R_{\mathrm{so}}<0.2\right), 68\left(0.2 \leq R_{\mathrm{s}} / R_{\mathrm{so}}<0.4\right)$, $75\left(0.4 \leq R_{\mathrm{s}} / R_{\mathrm{so}}<0.6\right), 48\left(0.6 \leq R_{\mathrm{s}} / R_{\mathrm{so}}<0.8\right)$, and $15(0.8 \leq$ $\left.R_{\mathrm{s}} / R_{\mathrm{so}} \leq 1.0\right)$, for each step used

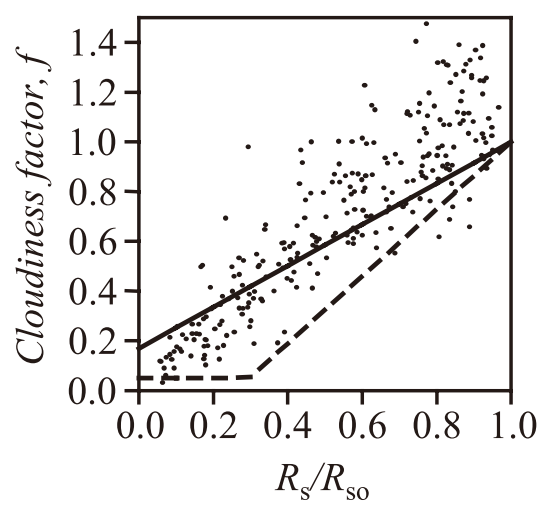

Figure 5. Relationship between the cloudiness factor $(f)$ and the ratio of the solar radiation to the clear sky solar radiation $\left(R_{\mathrm{s}} / R_{\mathrm{so}}\right)$. The solid line and dotted line show the $f$ values in step 3 and step 0 , respectively. The black circles show the $f$ values calculated by rearranging Equation (14) for 15 years (1998-2012)

Based on these results, calibrating the coefficients in the equation for the cloudiness factor $(f)$ improves the accuracy of the net longwave radiation estimation. On the contrary, the calibration of the coefficients in the Brunt and Ångström equations at Tateno is not effective, compared to the improvement by the calibration of the coefficients for the cloudiness factor. 


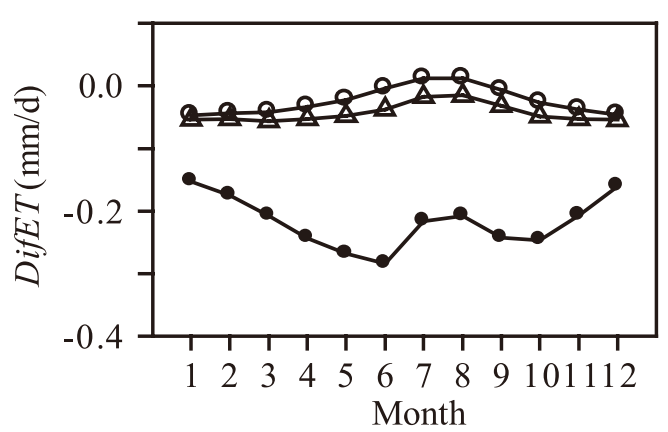

Figure 6. Monthly mean differences in the reference ET between the original FAO56-PM and modified calculations using the calibrated coefficients (DifET). The open circles, open triangles, and black circles denote the monthly mean DifET based on step 1, 2, and 3, respectively

\section{Reference ET calculation}

The monthly mean DifET estimated by each step is presented in Figure 6. The average value of monthly mean DifET from step 3 is $-0.21 \mathrm{~mm} \mathrm{~d}^{-1}$, whereas those from steps 1 and 2 are $-0.02 \mathrm{~mm} \mathrm{~d}^{-1}$ and $-0.04 \mathrm{~mm} \mathrm{~d}^{-1}$, respectively. Since the calibration effects of steps 1 and 2 are limited, these steps are not considered substantial. Instead, the calibration effect of step 3 is important because the estimated annual DifET values for the 15-year interval (i.e., 19982012) range from approximately $-70 \mathrm{~mm} \mathrm{y}^{-1}$ to $-80 \mathrm{~mm} \mathrm{y}^{-1}$, corresponding to approximately $10 \%$ of the annual reference ET calculated by the original FAO56-PM.

\section{CONCLUSIONS}

In the present study, the coefficients in the FAO56-PM net longwave radiation equation are calibrated using highly accurate net longwave radiation records. We draw the following main conclusions: (1) the original FAO56-PM net longwave radiation equation for the Tateno region is likely to underestimate the net longwave radiation and therefore overestimate the reference ET; (2) the net longwave radiation equation adopting the recommended coefficients has a RMSE of $1.11 \mathrm{MJ} \mathrm{m}^{-2} \mathrm{~d}^{-1}$ and MBE of $-0.34 \mathrm{MJ} \mathrm{m}^{-2} \mathrm{~d}^{-1}$ with respect to the observed net longwave radiation on the hypothetical reference surface; (3) at Tateno, the calibration of the coefficients in the equation for the cloudiness factor can be effective to improve the accuracy, whereas the calibration of coefficients in the Brunt and Ångström equations are not substantial.

\section{ACKNOWLEDGEMENTS}

We would like to thank the anonymous reviewers for valuable comments to improve the quality of the paper. This research has been supported and financed by Grants-in-Aid for Challenging Exploratory Research (24658198) from the Japan Society for the Promotion of Science.

\section{REFERENCES}

Allen RG. 2008. Quality assessment of weather data and micrometeorological flux - impacts on evapotranspiration calculation. Journal of Agricultural Meteorology 64: 191-204. DOI: 10. 2480/agrmet.64.4.5.

Allen RG, Smith M, Pereira LS, Perrier A. 1994. An update for the calculation of reference evapotranspiration. ICID Bulletin 43: 35-92.

Allen RG, Pereira LS, Raes D, Smith M. 1998. Crop evapotranspiration - Guidelines for computing crop water requirements. Irrigation and Drainage paper 56, FAO, Rome, Italy; 328.

Arking A. 1991. The radiative effects of clouds and their impact on climate. Bulletin of the American Meteorological Society 72: 795-813. DOI: 10.1175/1520-0477(1991)072<0795:TREOCA > 2.0.CO;2.

Brunt D. 1932. Notes on radiation in the atmosphere. I. Quarterly Journal of the Royal Meteorological Society 58: 389-420. DOI: $10.1002 / \mathrm{qj} .49705824704$.

Brutsaert W. 1982. Evaporation into the Atmosphere. D. Reidel Publishing Company, Dordrecht, Netherlands; 302.

Gong L, Xu CY, Chen D, Halldina S, Chen YD. 2006. Sensitivity of the Penman-Monteith reference evapotranspiration to key climatic variables in the Changiiang (Yangtze River) basin. Journal of Hydrology 329: 620-629. DOI: 10.1016/j.jhydrol. 2006.03.027.

Jensen ME, Burman RD, Allen RG. 1990. Evapotranspiration and irrigation water requirements. ASCE Manual 70. American Society of Civil Engineers. New York, USA; 332.

Kjaersgaard JH, Cuenca RH, Martínez-Cob A, Gavilán P, Plauborg F, Mollerup M, Hansen S. 2009. Comparison of the performance of net radiation calculation models. Theoretical and Applied Climatology 98: 57-66. DOI: 10.1007/s00704-008-0091-8.

Kuo SF, Ho SS, Liu CW. 2006. Estimation irrigation water requirements with derived crop coefficients for upland and paddy crops in ChiaNan irrigation association, Taiwan. Agricultural Water Management 82: 433-451. DOI: 10.1016/j.agwat.2005. 08.002 .

Monteith J, Unsworth M. 2007. Principles of Environmental Physics 3rd. Academic Press, London, UK; 440.

Ohkawara N, Takano M. 2008. Transition to the world infrared irradiance standard at Tateno station. Journal of Aerological and Observatory 68: 37-41 (in Japanese with English abstract).

Ohmura A, Dutton EG, Forgan B, Frohlich C, Gilgen H, Hegner H, Heimo A, Konig-Langlo G, McArthur B, Muller G, Philipona R, Pinker R, Whitlock CH, Dehne K, Wild M. 1998. Baseline surface radiation network (BSRN/WCRP), a new precision radiometry for climate research. Bulletin of the American Meteorological Society 79: 2115-2136. DOI: 10.1175/15200477(1998)079<2115:BSRNBW>2.0.CO;2.

Penman HL. 1948. Natural evaporation from open water, bare soil and grass. Proceedings of the Royal Society of London. Series A, Mathematical and Physical Sciences 193: 120-145. DOI: 10.1098/rspa.1948.0037.

Smith M. 1991. CROPWAT: Manual and Guidelines. FAO, Rome, Italy; 133.

Yin Y, Wu S, Zheng D, Yang Q. 2008. Radiation calibration of FAO56 Penman-Monteith model to estimate reference crop evapotranspiration in China. Agricultural Water Management 95: 77-84. DOI: 10.1016/j.agwat.2007.09.002.

Yoo SH, Choi JY, Jang MW. 2008. Estimation of design water requirement using FAO Penman-Monteith and optimal probability distribution function in South Korea. Agricultural Water Management 95: 845-853. DOI: 10.1016/j.agwat.2008. 02.010 . 